\title{
Recycled Plastic Composite Rod-Based Design of Fasteners in the Simplified Greenhouse
}

\author{
Cheng-Jung Yang, Ci-Hao Wang, Ying-Chieh Lee, and Meng-Hao Tsai
}

\begin{abstract}
The purpose of this study is to design fasteners of the simplified greenhouse by using rods made by recycled composite materials. The design process was composed of drawing the 3D model of the fastener and simulating torsion and tension forces caused by the 11-level wind to determine whether the strength of the designed fastener was sufficient. During the analysis, it was found that the material of stainless steel could increase the joint strength of the overall simple green house structure, which compensated the lack of strength of the rods. There was only a slight displacement and deformation at the joint of the fastener and the extent of deformation and displacement was insufficient to induce the fracture of the rods. Therefore, the designed fastener was able to tolerate most of the wind in the real world. The results of this study will contribute to the application and promotion of using rods made by recycled composite materials in the simplified greenhouse.
\end{abstract}

Index Terms-Fastener, simplified greenhouse, recycled composite material.

\section{INTRODUCTION}

Crops are indispensable parts of our lives nowadays. They are not only the fruits and vegetables we eat in daily life, but also have high ornamental and economic values. However, these high-value crops require more careful care and delicate environment than general crops. In order to achieve this cultivating condition, greenhouses are necessary. In the past, the greenhouse was to maintain the environment for planting. Under the protection, plants could be protected from external environmental influences, excessive water loss could be prevented, and temperature and humidity could be controlled. However, the price of a greenhouse was very expensive. Therefore, it was not economic to grow general crops in the greenhouse. Recently, a simplified greenhouse has been developed, which can provide shelter from wind and rain as well as avoid insects. The price is also lower. Therefore, it is more adopted by general farmers.

The design requirements for standard greenhouses can be found in the documents provided by the National Greenhouse Manufacturers Association (NGMA) [1]. Documents published in 2010 provide provisions for greenhouse loads

Manuscript received June 15, 2019; revised September 5, 2019. This work was supported by Ministry of Science and Technology, R.O.C., for financial support (MOST 107-2321-B-020-002).

Cheng-Jung Yang and Ci-Hao Wang are with the Department of Mechanical Engineering, National Pingtung University of Science and Technology, 1, Shuefu Road, Neipu, Pingtung 91201, Taiwan (e-mail: cjyang@mail.npust.edu.tw, deathless9227@gmail.com).

Ying-Chieh Lee is with the Department of Materials Engineering, National Pingtung University of Science and Technology, 1, Shuefu Road, Neipu, Pingtung 91201, Taiwan (e-mail: YCLee@mail.npust.edu.tw).

Meng-Hao Tsai is with the Department of Civil Engineering, National Pingtung University of Science and Technology, 1, Shuefu Road, Neipu, Pingtung 91201, Taiwan (e-mail: mhtsai@mail.npust.edu.tw). based on corresponding standards and minimum design loads for structures [2]. In addition, the EU's construction of standard greenhouses follows EN-13031-1, which provides rules for the design of greenhouse structures specific for professional production of plants and crops [3]. The functions of the greenhouse structure, including mechanical resistance, durability, applicability, and stability, is followed by Eurocode 1, ENV 1991-1 [4]-[6]. If the greenhouse structure is made by steel structure, Eurocode 3, ENV 1993 [7], can be referenced. The destruction of the greenhouse structure is mainly due to climatic behaviors, such as the movement of the rod, the bending of the arches, the failure of the covering net, uplifted foundation posts and the failure of the fastener [8]. In order to reduce the mistakes in greenhouse design, many researchers have used computer computing methods to analyze structures, loading and environments [9]-[11].

There are a lot of cases in which composite materials are applied in engineering, and some technologies are mature. For example, in the case of vehicle engineering, a composite frame can achieve less weight than general iron metal and achieve greater safety for passengers [12]. Another application is to extend the life cycle of vehicle parts. It is easy to disassemble when the parts go to the waste recycling stage, and improve the recovery rate of the basic parts [13]. Composite materials can also be used in windows as an energy saving tool. A recent research report points out that giving a composite coating on the window surface produces an infrared light-shielding effect that can increase the overall energy efficiency of the building by $40 \%$ [14].

Many plastic products are produced currently. Unfortunately, mostly plastic products cannot decompose or disappear in the general natural environment, causing environmental impacts and damages. In order to promote environmental protection, these plastic products have also been recycled into many recycled products recently. These industrial products made of recycled materials also have certain strength and practicality, and their weight is lighter than that of ordinary steel pipes. Some of the buildings in the market now also use these recycled plastic composites.

Therefore, the use of a variety of recycled plastics as a new material for product design has gradually become a trend. The plastic wire required for 3D printing in the FDM process has been studied by many people. The advantage is that this composite material can be utilized in the future customized market [15]. It also happened on railway transportation. A team made track fasteners from recycled plastics for mechanical analysis and understanding the feasibility of the application [16]. Based on the recycled materials, this study develops the fasteners assembled in a simplified greenhouse with light weight and simplicity to assemble, which fits the need for general household planting. 


\section{MATERIAL AND METHOD}

\section{A. Greenhouse in Taiwan}

In Taiwan, greenhouses are divided into three categories including structural greenhouses, simplified greenhouses, and net greenhouses. In addition, there are also great differences in the construction structure depending on the application. The structural greenhouse is equipped with water walls, fans, shade nets, and heating machines. It can actively adjust the temperature, ambient humidity, and air convection, as well as maintain the stability of the environment inside the greenhouse. This greenhouse is usually used for plants with high economic values such as orchids.

The simplified greenhouse is a simplified version of the structural greenhouse. It is usually applied to the cultivation of common crops. It can be used to block general wind, rain, and insects, as well as to reduce the overexposure and loss of water of plants. The structure of this greenhouse takes galvanized concrete pipe as rods, galvanized fasteners for joint assembly, and plastic or mesh cloth as an outside covering. The construction process is relatively simple, fast, and it is cheaper than the structural greenhouse. It is a relatively common type of greenhouses in the market. On the other hand, net greenhouses are mostly used in the production of general leafy vegetables and vegetable seedlings which cannot withstand large wind, rain, or direct sun exposure. The structure is mainly composed of short tunnels and the outer layer is covered with gauze. It has low structural strength and simplicity to disassemble, which is then used for short courses of planting.

\section{B. Fastener Design and Stress Analysis}

The rod of the simplified greenhouse is commonly a galvanized crucible tube in the market. In this study, recycling plastic composites are used instead because of the advantages of reducing the overall greenhouse weight, making assembly easier, and more environmentally friendly. The rod is made into a square hollow tube and material is synthesized from nylon PA+ and nylon glass fiber PAGF+PET, as shown in Fig. 1. After material testing, the rod had a Young's modulus of $37,000 \mathrm{kgf} / \mathrm{cm}^{2}$ and a tensile strength of $1050 \mathrm{kgf} / \mathrm{cm}^{2}$. In order to maintain the resistance of the fastener, the fastener material was changed from galvanized concrete to stainless steel (SUS 304). The tensile and flexural strength of the materials are shown in Table I.

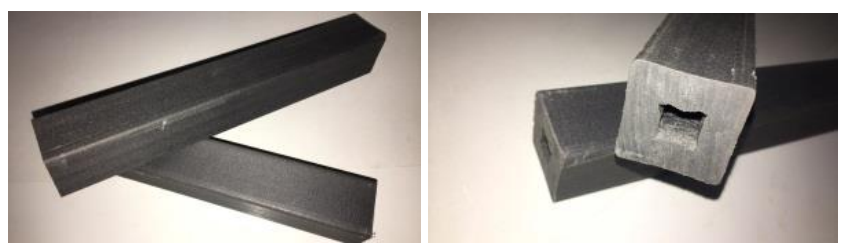

Fig. 1. The rod made by recycled plastic materials.

TABLE I: THE TENSILE AND FLEXURAL STRENGTH OF THE MATERIALS

\begin{tabular}{lll}
\hline \hline Channels & tensile strength & flexural strength \\
\hline Galvanized crucible & $270 \mathrm{MPa}$ & $200 \mathrm{MPa}$ \\
recycling plastic composites & $102.9 \mathrm{MPa}$ & $112.5 \mathrm{MPa}$ \\
SUS 304 & $520 \mathrm{MPa}$ & $205 \mathrm{MPa}$ \\
\hline \hline
\end{tabular}

In Taiwan, the stress sources of simplified greenhouses are mainly natural wind, typhoon, and rain. This study aims to evaluate the stress situation over a single windward surface, not in other specific conditions such as turbulence or cyclones. The stress situation over various parts of the fasteners was analyzed. The forces applied to different positions of fasteners were different in directions and amounts. This evaluation can be divided into three parts:

Roof (A and B): The roof of the greenhouse is designed in a triangular shape and the uppermost fastener is only loaded by the weight of the fixed rod and the gauze. This fastener within this part is the least stressed of the entire greenhouse structure.

Eaves (C to $\mathrm{E})$ : The fastener within this part is used to connect the roof and the base and to withstand the weight of the whole roof and the gauze. In addition, this is the windward side of the greenhouse; the forces come from all directions. Therefore, these fasteners are the most important part of the design.

Base ( $F$ and $G$ ): The fasteners within this part are used to fix the position of the overall greenhouse. The four fasteners are connected to the foundation to allow the entire greenhouse to be fixed. The force is the weight of the entire greenhouse and the gauze. When subjected to wind, the greenhouse will pull the fasteners.

During the design process, initially the 3D drawings of the 7 fasteners required for the simplified greenhouse was drawn, and then the stress of these fasteners was analyzed to know the stress situation and structural strength of the fasteners. Both 3D drawing and force analysis were performed using the computer aided design software of Autodesk Inventor. The 3D model of simple green house is shown in Fig. 2.

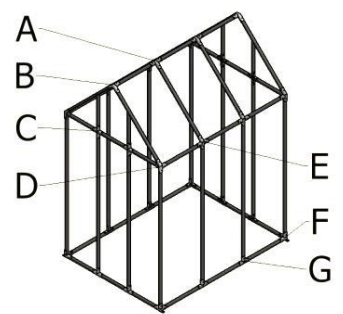

Fig. 2. The rod made by recycled plastic materials.
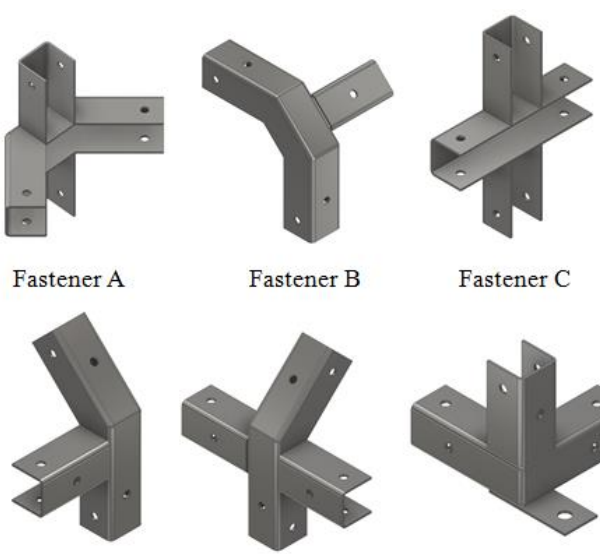

Fastener C

Fastener D

Fastener E

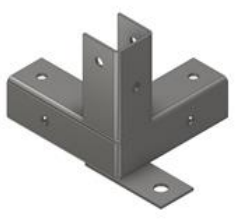

Fastener F

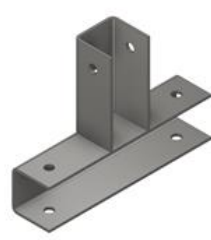

Fastener G

Fig. 3. The 3D drawings of fasteners from A to $G$. 
There were two roof fasteners. Fastener A supported the middle part of the roof, and fastener B for the anterior and posterior part of the roof. There were three eave fasteners. Fastener C supported the horizontal and vertical rod of the anterior part of greenhouse, fastener D for surrounding support, and fastener $\mathrm{E}$ for the central support of the crossbar. There were two base fasteners. Fastener $F$ fixed the four angles of the foundation, and fastener $G$ localized the crossbar and the upright support. All fasteners had a thickness of $2 \mathrm{~mm}$ and a depth of $70 \mathrm{~mm}$ with the rod. The 3D drawings of fasteners from A to $\mathrm{G}$ are as shown in Fig. 3.

For the force analysis, the 3D drawing of the fastener was first imported into the interface of software, then the material properties of fasteners were established, finite element mesh segmentation was performed, and finally the forces in XYZ axes were set. This study evaluated the force on the windward side, mainly analyzing the fastener E, D, F, and G. In addition, the force on the bolts fixing between fasteners and the rod was evaluated, too.

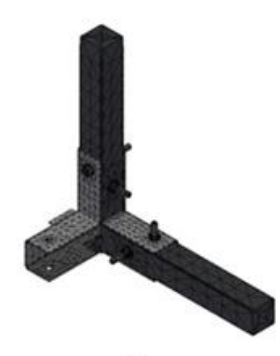

(a)

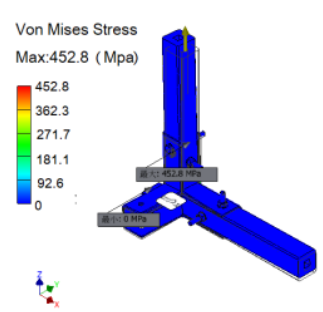

(c)

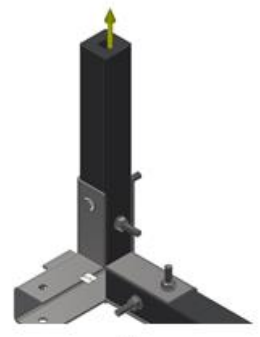

(b)

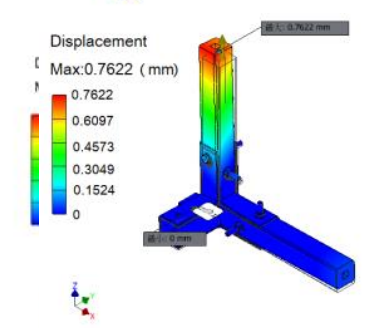

(d)

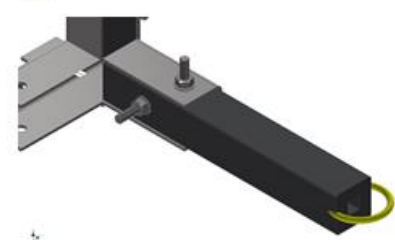

(e)

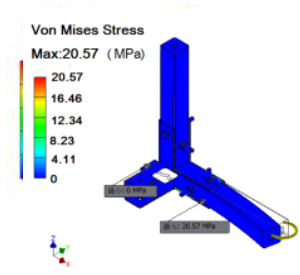

(f)

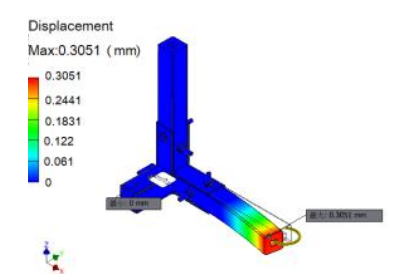

(g)
Fig. 4. The stress analysis in fastener F.

\section{RESULT AND DISCUSSION}

In this study, the tension and torsion of the simplified greenhouse was evaluated under the setting of 11th level of typhoon. The axial tensile force was $4116 \mathrm{~N}$ and the torsional force was $6825 \mathrm{kgf}-\mathrm{m}$. The stress and displacement analysis of the four fasteners E, D, F and G were carried out.

\section{A. Fastener $F$}

The result of finite element segmentation is shown in Fig. $4(\mathrm{a})$. The rod was subjected to a pulling force of $4116 \mathrm{~N}$, as shown in Fig. 4(b). After analysis, the maximum Von Mises stress was $452.8 \mathrm{MPa}$, as shown in Fig. 4(c). The maximal displacement was $0.7622 \mathrm{~mm}$, as shown in Fig. 4(d). In addition, another force analysis was performed. The rod was subjected to a torque of $6825 \mathrm{kgf}-\mathrm{m}$, as shown in Fig. 4(e). After simulation, the maximal Von Mises stress was 20.57 $\mathrm{MPa}$, as shown in Fig. 4(f). The maximum displacement was $0.3051 \mathrm{~mm}$, as shown in Fig. 4(g).

\section{B. Fastener $G$}

The result of finite element segmentation is shown in Fig. 5(a). The rod was subjected to a torque of $6825 \mathrm{kgf}-\mathrm{m}$, as shown in Fig. 5(b). After the force analysis, the maximal Von Mises stress was 12.6 MPa, as shown in Fig. 5(c). The maximum displacement was $1.306 \mathrm{~mm}$, as shown in Fig. $5(d)$.

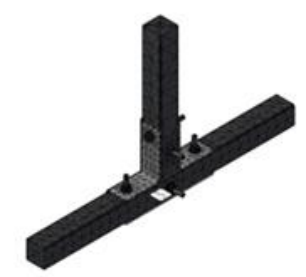

(a)

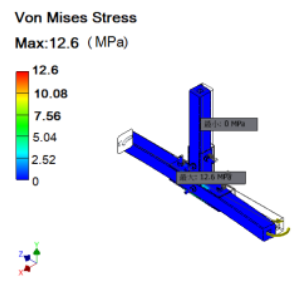

Fig. 5. The stress analysis in fastener G.

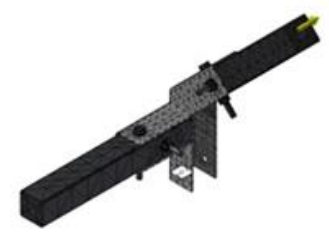

(a)

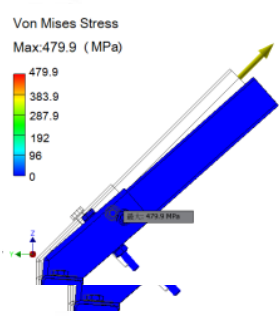

(c)

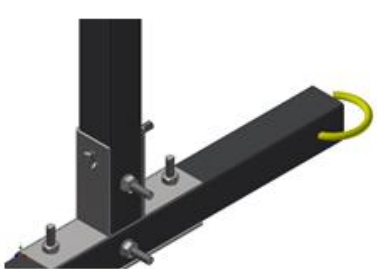

(b)

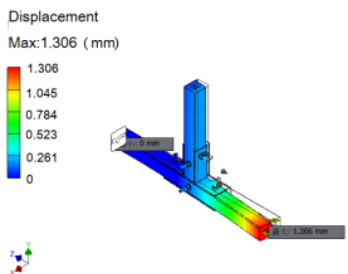

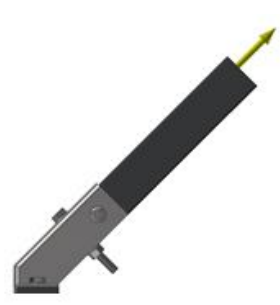

(b)

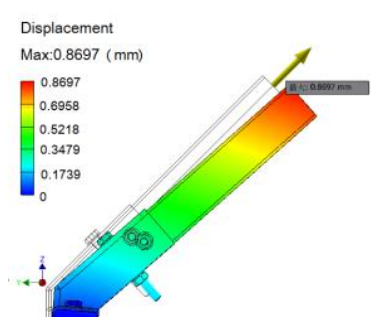

(d)

Fig. 6. The stress analysis in fastener D.

\section{Fastener D}

The result of finite element segmentation is shown in Fig. 
6(a). The rod was subjected to a pulling force of $4116 \mathrm{~N}$, as shown in Fig. 6(b). After the force analysis, the maximal Von Mises stress was $479.9 \mathrm{MPa}$, as shown in Fig. 6(c). The maximum displacement was $0.8697 \mathrm{~mm}$, as shown in Fig. 6(d).

\section{Fastener $E$}

The result of finite element segmentation is shown in Fig. 7(a). The rod was subjected to a torque of $6825 \mathrm{kgf}-\mathrm{m}$, as shown in Fig. 7(b). The maximal Von Mises stress after the force analysis was $69.54 \mathrm{MPa}$, as shown in Fig. 7(c). The maximal displacement was $0.3081 \mathrm{~mm}$, as shown in Fig. $7(\mathrm{~d})$.

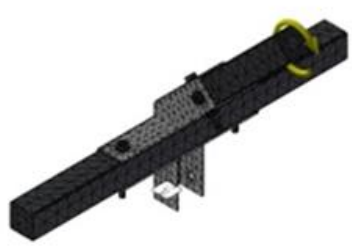

(a)

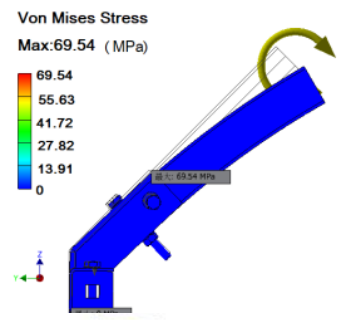

(c)

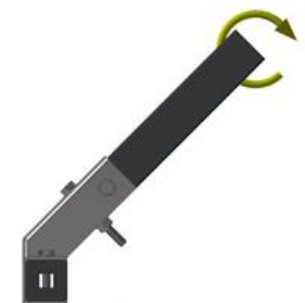

(b)

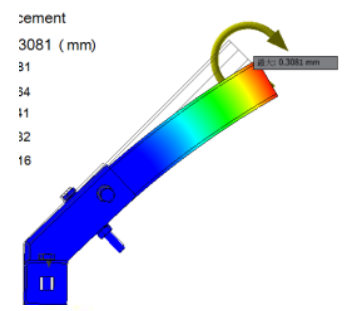

(d)
Fig. 7. Magnetization as a function of applied field.

\section{CONCLUSION AND FUTURE WORK}

According to the simulation results, the stress over the fastener was focused at the junction, which made it slightly deformed. The Von Mises stress did not exceed the maximal shear stress of the fastener, thus it indicated that the fastener would not break due to strong wind. With regard to deformation, the maximal displacement occurred on the rod. It indicated that all fasteners would only have some slight deformation without being broken before the breakage of the rod. The results above showed that the overall fastener strength obtained by the material and structural design could fit the requirement in real world. At present, square rods are not so commonly used. The next step of this study will be adjustment in shapes of the rods and fasteners, in which circular rods will be used instead, to promote further application of recycled plastic composite-based rods for the simplified greenhouse.

\section{ACKNOWLEDGMENT}

The authors would like to thank the Ministry of Science and Technology, R.O.C., for financial support (MOST 107-2321-B-020-002).

\section{REFERENCES}

[1] NGMA. (2016). Structural design manual. [Online]. Available: https://www.ngma.com

[2] ASCE/SEI7. (2010). Minimum design loads for buildings and other structures. American Society of Civil Engineers, Structural
Engineering Institute. [Online]. Available: http://www.asce.org/structural-engineering/asce-7-and-seistandards/

[3] CEN, EN-13031e1: Greenhouses: Design and construction Part 1: Commercial production greenhouses. Brussels: Comit'e Europ'een de Normalisation, 2001.

[4] CEN, EN-1991-1-1: Actions on structures Part 1-1: General actions e Densities, self-weight, imposed loads for buildings, Brussels: Comit'e Europ'een de Normalisation, 2002.

[5] CEN, EN-1991-1-3: Actions on structures Part 1-3: General actions e Snow loads. Brussels: Comit'e Europ'een de Normalisation, 2003.

[6] CEN, EN-1991-1-4: Actions on structures - General actions Part 1-4 Wind actions. Brussels: Comit'e Europ'een de Normalisation, 2005a.

[7] CEN, EN-1993-1-1: Design of steel structures Part 1-1: Generalrules and rules for buildings. Brussels: Comit'e Europ'een de Normalisation, $2005 b$

[8] J. Bartok. (2010). Reducing storm damage to your greenhouses. UMass Center for Agriculture, Food and the Environment. University of Massachusetts Amherst. [Online]. Available: https://ag.umass.edu/fact-sheets/reducing-storm-damage-to-your-gree nhouses

[9] D. Briassoulis, "Mechanical design requirements for low tunnel biodegradable and conventional films," Biosystems Engineering, vol. 87, no. 2, pp. 209-223, 2004.

[10] Q. Fei et al., "Features of load effects and application in designing Venlo greenhouse," Transactions of the Chinese Society of Agricultural Engineering, vo. 23, no. 3, pp. 163-168, 2007.

[11] F. D. Molina-Aiz, H. Fatnassi, T. Boulard, J. C. Roy, and D. L. Valera, "Comparison of finite element and finite volume methods for simulation of natural ventilation in greenhouses," Computers and Electronics in Agriculture, vol. 72, no. 2, pp. 69-86, 2010.

[12] A. G. Mamalis, Crashworthiness of Composite Thin-Walled Structures, New York: Routledge, 1998.

[13] R. I. Li, A. V. Butin, S. P. Ivanov, and D. V. Mashin, "A promising polymer composite material for increasing the efficiency of recovery of basic parts of automotive engineering," Polymer Science Series D, vol. 7, no. 3, pp. 233-237, 2014.

[14] Y. Gao, W. Yao, J. Sun, H. Zhang, Z. D. Wang, L. Wang, D. Yang, L. Zhang, and H. Yang, "A novel soft matter composite material for energy-saving smart windows: From preparation to device application," Journal of Materials Chemistry A, vo. 20, no. 20, pp. 10613-11138, 2015.

[15] N. Mohan, P. Senthil, S. Vinodh, and N. Jayanth, "A review on composite materials and process parameters optimisation for the fused deposition modelling process," Virtual and Physical Prototyping, vol. 12, no. 1, pp. 47-59, 2017.

[16] I. Lotfy, M. Farhat, and M. A. Issa, "Structural behavior of rail fastening system used for recycled plastic composite crossties," in Proc. the 2015 Joint Rail Conference, 2015.

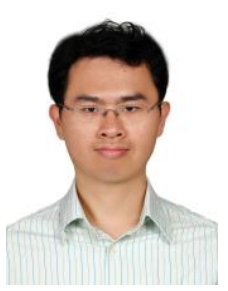

Cheng-Jung Yang was born in Kaohsiung, Taiwan on May 21, 1982. He received the master and the Ph.D degree from the Department of Mechanical Engineering in National Cheng Kung University in 2006 and 2011, respectively. He is currently an assistant professor in the Department of Mechanical Engineering, National Pingtung University of Science and Technology. He is the head of the EMPD laboratory and also manages the 3D printing center of NPUST. He is involved in the research of 3D printing, internet of thing (IoT), medical device design, sustainable design and their applications.

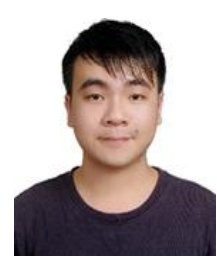

Ci-Hao Wang was born in Tainan, Taiwan. He earned her bachelor's degree in the College of Mechanical Engineering, National Pingtung University of Science and Technology, in 2018. He is currently studying mechanical design and mechanical analysis at the College of Mechanical Engineering, National Pingtung University of Science and Technology.

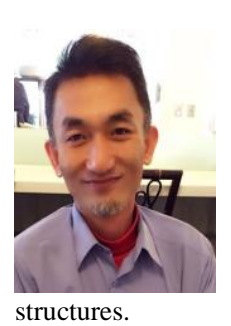

Meng-Hao Tsai was born in Taichung, Taiwan and earned his $\mathrm{PhD}$ degree in the College of Engineering, National Taiwan University in 1998. He is currently a professor of the Civil Engineering Department at National Pingtung University of Science and Technology. He has been engaged in the field of structural engineering for over two decades. His research interests include structural analysis, seismic isolation, and progressive collapse response of 